\title{
PERAWATAN KAKI TERHADAP PERUBAHAN UJI SENSITIVITAS KAKI PADA PENDERITA DM TIPE 2
}

\author{
(Foot Care On The Peripheral Neuropathy Sensitivity In Type 2 Diabetic Patients In Southern \\ Pontianak Public Health Center)
}

\author{
Agung Nur Rasyid*, Nita Arisanti Yulanda*, Suhaimi Fauzan* \\ *Prodi Keperawatan Fakultas Kedokteran Universitas Tanjungpura, Pontianak \\ Email : agungnf123@gmail.com
}

\begin{abstract}
ABSTRAK
Latar Belakang : Neuropati periferal merupakan salah satu komplikasi pada penderita DM tipe 2 yang ditandai dengan sensivitas kaki menurun sehingga dapat mengakibatkan perlukaan pada kaki, deteksi dini sensitivitas kaki sangat penting untuk mencegah perlukaan pada kaki dan amputasi, hasil uji sensitivitas kaki yang buruk akan mengakibatkan penderita tidak bisa merasakan sentuhan pada kakinya sehingga diperlukan intervensi berupa perawatan kaki yang dapat membuat hasil uji sensitivitas kaki menjadi lebih baik.

Tujuan: Penelitian ini bertujuan melihat pengaruh perawatan kaki terhadap perubahan uji sensitivitas kaki pada penderita DM Tipe 2 di wilayah UPTD Puskesmas Pontianak Selatan

Metode: Penelitian kuantitatif yang menggunakan desain penelitian quasy experiment dengan jenis penelitian pre and post test dengan simple random sampling yang mana menggunakan satu kelompok intervensi dan satu kelompok kontrol pada responden sebanyak 36 orang dengan menggunakan instrumen uji sensitivitas kaki berupa monofilamen $10 \mathrm{~g}$ dan Garputala $128 \mathrm{~Hz}$.

Hasil : uji Mann Whitney menunjukkan bahwa ada perbedaan yang signifikan perawatan kaki terhadap perubahan uji sensitivitas kaki $(\rho=0,000)$ pada penderita DM Tipe 2 yang mengalami neuropati periferal..

Kesimpulan : Ada pengaruh perawatan kaki terhadap perubahan uji sensitivitas kaki neuropati periferal pada pasien DM tipe 2 di wilayah UPTD Puskesmas Pontianak Selatan.

Kata Kunci : Perawatan Kaki, Neropati Periferal, Uji Sensitivitas Kaki

Referensi : 24 (2008-2018)
\end{abstract}




\begin{abstract}
Background: Peripheral neuropathy is one of the complications in patients with type 2 DM characterized by decreased leg sensitivity so that it can cause injury to the foot, early detection of foot sensitivity is very important to prevent foot injury and amputation, the results of poor foot sensitivity testing will result in sufferers unable to feel the touch on his feet so that an intervention in the form offoot care is needed which can make the results of the foot sensitivity test better.

Aim: The purpose of current study is to investigate the effect of foot care on foot's sensorics sensitivity in patients with type 2 DM in Southern Pontianak Public Health Center.

Method: Quantitative reseach using quasy experiment research design with a type of pre and post test with simple random sampling which used intervention group and one control group for 36 respondens using a foot sensivity test in the form of 10-g monofilament test and $128 \mathrm{~Hz}$, tuning fork.

Result: The analysis using Mann-Whitney test shows there was a significant difference $(p=0.000)$ in patients with type 2 diabetes mellitus who had peripheral neuropathy.

Conclusion: There was a significant effect of foot care on the foot's peripheral sensorics sensitivity in type 2 DM patients in Southern Pontianak Public Health Center. Keywords: foot care, DM type 2, peripheral neuropathy, foot sensitivity test Reference:24 (2008-2018)
\end{abstract}




\section{PENDAHULUAN}

Penyakit Kronis merupakan penyakit yang berkembang secara perlahan selama bertahun-tahun namun biasanya tidak dapat disembuhkan melainkan hanya diberikan penanganan kesehatan ${ }^{1}$. Salah satu penyakit kronis adalah Diabetes Melitus (DM), penyakit DM merupakan kumpulan gejala yang timbul pada seseorang karena peningkatan kadar glukosa darah akibat penurunan sekresi insulin ${ }^{2}$.

Jumlah penderita DM di dunia semakin bertambah setiap tahunnya. Hal ini dapat disebabkan karena peningkatan jumlah populasi, usia, prevalensi obesitas dan penurunan aktivitas fisik ${ }^{3}$. Menurut International Diabetes Federation ( IDF) ATLAS, 2017 prevalensi DM di dunia mencapai 425 juta jiwa dan diperkirakan akan mencapai 628,6 juta jiwa pada tahun 2045. Indonesia merupakan negara dengan penderita DM terbanyak ke enam di dunia dengan jumlah penderita DM mencapai 10,3 juta jiwa. Diperkirakan angka tersebut akan terus mengalami kenaikan hingga mencapai 16,7 juta jiwa pada tahun $2045 .{ }^{4}$

Menurut data dari Laporan hasil RISKESDAS tahun 2018 untuk provinsi Kalimantan Barat menunjukkan bahwa prevalensi DM berdasarkan hasil pemeriksaan darah sebesar 1,8\%. Data dari Dinas Kesehatan Kota Pontianak yang dihimpun dari seluruh puskesmas di Pontianak pada tahun 2018 berjumlah sebanyak 44.003 jiwa dengan puskesmas gang sehat yang memiliki penderita DM terbanyak di Kota Pontianak sebanyak 3.759 jiwa. $^{5}$

Tingginya angka kejadian DM sebagian besar merupakan golongan DM tipe II yang disebabkan oleh interaksi antara faktor-faktor kerentanan genetis dan lingkungan ${ }^{6}$, salah satu komplikasi DM tipe 2 yaitu komplikasi mikrovaskuler yang dapat menyebabkan terjadinya neuropati periferal $^{7}$, neuropati periferal ini dapat menyebabkan penderita
Diabetes Melitus mengalami penurunan sensitivitas kaki ${ }^{8}$.

Menurut National Diabetes Information Clearinghouse (NDIC) (2013), 60-70\% klien Diabetes Melitus mengalami neuropati. Di Indonesia neuropati berada pada urutan ketiga tertinggi komplikasi akibat Diabetes ${ }^{6}$. Hilangnya sensasi merupakan salah satu faktor utama risiko terjadinya ulkus. Ulkus kaki diabetik merupakan komplikasi menahun yang paling ditakuti oleh DM, baik ditinjau dari lamanya perawatan, biaya tinggi yang diperlukan untuk pengobatan yang menghabiskan dana 3 kali lebih banyak dibandingkan tanpa ulkus ${ }^{8}$.

Berdasarkan hasil studi pendahuluan terhadap 10 penderita DM tipe 2 di UPTD Puskesmas Pontianak Selatan didapatkan bahwa 8 dari 10 penderita sering mengalami mati rasa pada kaki dan kaki terasa sakit, panas, dan juga merasakan dingin yang kuat pada malam hari. Gejala neuropati ini paling terasa pada tungkai bawah dan kaki sebelah kanan dan kiri. Yang paling menyiksa dapat meyebabkan nyeri berdenyut terus menerus. Pasien tidak menyadari bahkan sering mengabaikan luka yang terjadi karena tidak dirasakannya. Luka timbul spontan sering disebabkan karena trauma misalnya kemasukan pasir, tertusuk duri, lecet akibat pemakaian sepatu/sandal yang sempit dan bahan yang keras ${ }^{9}$. Neuropati perifer merupakan salah satu komplikasi serius dari Diabetes. Jika dibiarkan maka dapat beresiko terjadi ulkus diabetik. Ulkus kaki diabetik merupakan penyebab masalah umum hospitalisasi pada pasien Diabetes dan penyebab utama nontraumatik yang mengakibatkan amputasi pada ekstremitas bawah ${ }^{10}$.

Deteksi dini DPN sangat penting untuk mencegah borok pada kaki dan amputasi. Beberapa metode digunakan untuk mendeteksi DPN, termasuk pengujian sensorik kuantitatif, sistem penilaian pemeriksaan fisik (misalnya, skor 
ketidakmampuan neuropati), Nerve Conduction Studies (NCS) atau studi konduksi saraf, dan tes elektrodiagnostik. NCS dianggap sebagai standar untuk diagnosis DPN, tetapi pemeriksaan ini terlalu memakan waktu, sangat menuntut, dan mahal untuk diimplementasikan dibanyak pengaturan perawatan primer, oleh sebab itu alat yang portabel, bagus, valid, dan terjangkau untuk mendeteksi DPN yaitu menggunakan tes monofilamen yang digunakan untuk uji sensitivitas nyeri ${ }^{11}$ dan garpu tala $128 \mathrm{~Hz}$ untuk mengukur persepsi vibrasi $^{12}$.

Salah satu tindakan yang direkomendasikan oleh American Diabetes Association, 2016 adalah pelayanan multidisiplin tim yang melibatkan beberapa bidang keilmuwan termasuk keperawatan. Peran perawat yaitu melakukan promosi kesehatan, upaya preventif penyakit, dan perawatan pasien bagi penderita DM tipe 2 . Promosi kesehatan mempunyai pengertian yaitu upaya kesehatan yang menyeluruh, yaitu preventif, promotif, dan kuratif, dan mulai dikenal lebih luas setelah konferensi Internasional Promosi Kesehatan ${ }^{13}$. Salah satu teori keperawatan yang menekankan pada upaya promotif dan preventif adalah Nola J. Pender tentang Health Promotion Model (HPM) yang menjelaskan bahwa perilaku kesehatan merupakan hasil tindakan yang ditujukan untuk mendapatkan hasil kesehatan yang optimal ${ }^{14}$.

Berdasarkan hasil studi pendahuluan terhadap 10 penderita DM tipe 2 di UPTD Puskesmas Pontianak Selatan didapatkan bahwa 7 dari 10 penderita tidak melakukan perawatan kaki, karena kurangnya edukasi tentang perawatan kaki terutama mencuci kaki menggunakan air hangat dan memotong kuku kaki secara benar, oleh sebab itu peran perawat sebagai pemberi pelayanan kepada pasien Diabetes Melitus yaitu sebagai upaya preventif terhadap ulkus diabetik bahkan mencegah resiko terjadinya amputasi ektremitas bawah, salah satunya melalui praktik perawatan kaki. Perawat tidak hanya memfasilitasi dan memberikan perawatan kaki, tetapi juga dapat memberikan edukasi kepada keluarga tentang pentingnya kunjungan ke klinik untuk melakukan pengecekan gula darah serta bagaimana upaya yang dapat dilakukan untuk mencegah terjadinya komplikasi akibat Diabetes melitus tipe 2 dan upaya perawatan kaki untuk mencegah terjadinya ulkus ${ }^{10}$.

Menurut The Centers for Disease Kontrol and Prevention bahwa perawatan kaki secara teratur dapat mengurangi penyakit kaki diabetik sebesar 50-60\% yang mempengaruhi kualitas hidup ${ }^{12}$. Penelitian yang dilakukan oleh Embuai, s., Lestari, P., Ulfina, e., 2017 bahwa setelah dilakukan intervensi perawatan kaki selama 3 bulan didapatkan bahwa semua responden yang mengalami neuropati peripheral sebanyak 41 responden mengalami perbaikan kearah positif dan 6 responden masih mengalami neuropati.

Berdasarkan uraian fenomena di atas, peneliti tertarik untuk melakukan penelitian tentang Perawatan Kaki Terhadap perubahan uji sensitivitas kaki neuropati periferal pada Penderita DM tipe 2 di wilayah UPTD Puskesmas Pontianak Selatan.

\section{METODE}

Jenis penelitian ini adalah penelitian kuantitatif menggunakan desain penelitian quasy experiment dengan jenis penelitian pre and post test dengan simple random sampling. proses penelitian dilakukan selama 3 bulan yaitu pada tanggal 26 Maret - 36 Juni 2019 di wilayah UPTD Puskesmas Pontianak Selatan. Jumlah responden yang digunakan sebanyak 36 responden yang terdiri dari 18 kelompok intervensi dan 18 kelompok kontrol. Kelompok Intervensi adalah kelompok yang diberikan intervensi perawatan kaki sedangkan pada kelompok 
kontrol responden diberikan edukasi mengontrol gula darah.

Instrumen pada penelitian ini adalah $\mathrm{Uji}$ Monofilamen 10g dan Garputala $128 \mathrm{~Hz}$. Analisis data pada penelitian ini menggunakan analisis statistik komputer. pengolahan data yang telah terkumpul dilakukan dengan menggunakan frekuensi untuk analisis univariat, dan analisis bivariat menggunakan uji Wilcoxon untuk melihat pengaruh perawatan dan uji Mann Whitney untuk melihat perbedaan hasil post test intervensi pada kedua kelompok penelitian.

\section{HASIL}

\section{Analisis Univariat}

Tabel 1 Distribusi Karakteristik Responden Berdasarkan Usia, Jenis Kelamin, Lama Menderita DM, dan Riwayat Merokok pada Kelompok intervensi dan kelompok kontrol $(\mathrm{n}=36)$.

\begin{tabular}{ccccc}
\hline \multirow{2}{*}{ Karakteristik } & \multicolumn{2}{c}{ Intervensi } & \multicolumn{2}{c}{ Kontrol } \\
\cline { 2 - 5 } & $\boldsymbol{f}$ & $\mathbf{\%}$ & $\boldsymbol{f}$ & $\mathbf{\%}$ \\
\hline Usia & & & & \\
\hline Dewasa Akhir & 4 & 22,2 & 5 & 27,8 \\
$\quad$ (36-45 Tahun) & 5 & 27,8 & 8 & 44,4 \\
Lansia Awal & 9 & 50 & 5 & 27,8 \\
$\quad$ (46-55 Tahun) & & & & \\
Lansia Akhir & & & & \\
$\quad$ (56-65 Tahun) & & & & \\
\hline Jenis Kelamin & & & & \\
\hline Laki-laki & 7 & 38,9 & 7 & 38,9 \\
\hline Perempuan & 11 & 61,1 & 11 & 61,1 \\
\hline Lama Menderita & & & & \\
DM $\quad$ & & & & \\
\hline$\quad$ > 3 tahun & 8 & 44,4 & 7 & 38,9 \\
> 5 tahun & 10 & 55,6 & 11 & 61,1 \\
\hline Riwayat Merokok & & & \\
\hline Merokok & 6 & 33,3 & 5 & 27,8 \\
Tidak Merokok & 12 & 66,7 & 13 & 72,2
\end{tabular}

Sumber : Data Primer (2019)

Data pada tabel. 1 menunjukkan bahwa pada kelompok intervensi, kategori usia responden sebagian besar pada rentang usia lansia akhir yaitu (56-65 tahun) dengan persentase $50 \%$. Jumlah responden sebagian besar berjenis kelamin perempuan dengan persentase $61,1 \%$. Lama menderita DM pada kelompok intervensi sebagian besar lebih dari 5 tahun dengan presentase $55,4 \%$. Kelompok intervensi sebagian besar tidak memiliki riwayat merokok dengan persentase $66,7 \%$. Pada kelompok kontrol Kategori usia responden sebagian besar pada rentang usia lansia awal (46-55 tahun) dengan persentase $44,4 \%$, pada kelompok kontrol hampir seluruhnya berjenis kelamin perempuan dengan persentase $61,1 \%$. Lama menderita DM pada kelompok kontrol sebagian besar lebih dari 5 tahun dengan presentase $61,1 \%$. dan pada kelompok kontrol sebagian besar tidak pernah memiliki riwayat merokok dengan persentase $72,2 \%$

Tabel. 2 Karakteristik Nilai Gula Darah Sewaktu Sebelum dan sesudah diberikan Senam Ergonomik Pada Kelompok Perlakuan Dan Kelompok Kontrol perawatan kaki $(n=36)$

\begin{tabular}{|c|c|c|c|c|}
\hline \multirow{2}{*}{ Nilai GDS } & \multicolumn{2}{|c|}{ Sebelum } & \multicolumn{2}{|c|}{ Sesudah } \\
\hline & $f$ & $\%$ & $f$ & $\%$ \\
\hline \multicolumn{5}{|l|}{$\begin{array}{l}\text { Kelompok } \\
\text { Intervensi }\end{array}$} \\
\hline$>200$ & 18 & 100 & 5 & 27,8 \\
\hline$<200$ & 0 & 0 & 13 & 72,2 \\
\hline \multicolumn{5}{|l|}{$\begin{array}{l}\text { Kelompok } \\
\text { Kontrol }\end{array}$} \\
\hline$>200$ & 18 & 100 & 7 & 38,9 \\
\hline$<200$ & 0 & 0 & 11 & 61,1 \\
\hline \multicolumn{5}{|c|}{ Sumber : Data Primer, 2019} \\
\hline \begin{tabular}{l}
\multicolumn{1}{c}{ Data } \\
kelompok \\
intervensi \\
normal de \\
dilakukan \\
menjadi \\
kelompok \\
sebelum \\
responden \\
dengan per \\
intervensi \\
penurunan
\end{tabular} & $\begin{array}{r}\text { ta } \\
\text { ven } \\
\text { uhr } \\
\text { pe } \\
\text { ven } \\
\% \\
\text { ven } \\
\text { erik } \\
\text { mil } \\
\text { ase } \\
\text { kel } \\
\text { jadi }\end{array}$ & $\begin{array}{c}2 \\
\text { eraw } \\
\text { men } \\
\text { atase } \\
\text { mens } \\
\text { ama } \\
\text { ada } \\
\text { int } \\
\text { GD } \\
\% . \\
\text { ok } \\
1 \%\end{array}$ & $\begin{array}{l}\mathrm{i} \\
\mathrm{kal} \\
\mathrm{i} \mathrm{G} \\
0 \\
\mathrm{ni} \\
\mathrm{ln} \\
\mathrm{mp} \\
\mathrm{msi} \\
\text { iata } \\
\text { lah } \\
\text { ol }\end{array}$ & $\begin{array}{l}\text { pada } \\
\text { ebelum } \\
\text { diatas } \\
\text { Setelah } \\
\text { urunan } \\
\text { dengan } \\
\text { kontrol } \\
\text { seluruh } \\
\text { normal } \\
\text { akukan } \\
\text { galami }\end{array}$ \\
\hline
\end{tabular}




\section{Analisis Bivariat}

Tabel 4 Distribusi Nilai Uji Sensitivitas Kaki menggunakan Monofilamen $10 \mathrm{~g}$ dan Garputala 128 $\mathrm{Hz}$ Sebelum Dan Setelah Intervensi Perawatan Kaki Pada Kelompok Perlakuan Dan Kelompok Kontrol Sumber: Uji Wilcoxon (2019)

\begin{tabular}{|c|c|c|c|c|}
\hline Variabel & $\begin{array}{c}\text { Kelompok } \\
(n=36)\end{array}$ & SD & $\begin{array}{c}\text { Median } \\
\text { (Min- } \\
\text { Max) }\end{array}$ & $\rho$ \\
\hline Monofilamen & \multirow{8}{*}{ Intervensi } & 2,055 & 5,44 & \multirow{4}{*}{0,000} \\
\hline Pretest & & & $(1-7)$ & \\
\hline Monofilamen & & 1,263 & 8,27 & \\
\hline Posttest & & & $(5-10)$ & \\
\hline Garputala & & 3,964 & 11,3 & \multirow{4}{*}{0,001} \\
\hline Pretest & & & $(3-17)$ & \\
\hline Garputala & & 3,680 & 5,12 & \\
\hline Posttest & & & $(1-15)$ & \\
\hline Monofilamen & \multirow{8}{*}{ Kontrol } & 1,862 & 5,40 & \multirow{4}{*}{0,000} \\
\hline Pretest & & & $(1-7)$ & \\
\hline Monofilamen & & 1,199 & 6,77 & \\
\hline Posttest & & & $(3-8)$ & \\
\hline Garputala & & 5,426 & 9,00 & \multirow{4}{*}{0,001} \\
\hline Pretest & & & $(2-18)$ & \\
\hline Garputala & & 4,696 & 5,00 & \\
\hline Posttest & & & $(2-15)$ & \\
\hline
\end{tabular}

Sumber: Hasil Uji Wilcoxon (2019)

Berdasarkan tabel. 4 didapatkan bahwa nilai $p$ value monofilamen $10 \mathrm{~g}$ kelompok intervensi sebesar 0,000 kemudian nilai $p$ value garputala $128 \mathrm{~Hz}$ kelompok intervensi sebesar 0,001. Kelompok kontrol pada penelitian nilai $p$ value monofilamen $10 \mathrm{~g}$ sebesar 0,000 . nilai $p$ value garputala $128 \mathrm{~Hz}$ sebesar 0,001. Suatu data dikatakan memiliki pengaruh jika memiliki nilai $p$ value $<0,05$. Jadi dapat disimpulkan bahwa ada pengaruh intervensi perawatan kaki terhadap perubahan nilai uji sensitivitas kaki pada kedua kelompok.
Tabel 5 Uji Perbedaan Nilai Uji Sensitivitas Kaki Antara Kelompok Intervensi dan Kelompok Kontrol

\begin{tabular}{lcccc}
\hline Variabel & $\begin{array}{c}\text { Kelompok } \\
(\mathbf{n = 3 6 )}\end{array}$ & SD & $\begin{array}{c}\text { Median } \\
(\text { Min- } \\
\text { Max })\end{array}$ & $\boldsymbol{\rho}$ \\
\hline Monofilamen & $\begin{array}{c}\text { Intervensi } \\
\text { Kontrol }\end{array}$ & 1,538 & $\begin{array}{c}2,29 \\
(0-6)\end{array}$ & 0,000 \\
Garputala & $\begin{array}{c}\text { Intervensi } \\
\text { Kontrol }\end{array}$ & 2,478 & $\begin{array}{c}2,57 \\
(0-9)\end{array}$ & 0,000 \\
\hline
\end{tabular}

Sumber: Hasil Uji Mann Whitney (2019)

Analisa pada tabel 5 di atas dapat disimpulkan bahwa hasil dari uji statistik menggunakan uji Mann Whitney diperoleh nilai $\rho=0,000$ pada kelompok kontrol dan intervensi $(\mathrm{p}>0,05)$, artinya ada perbedaan hasil uji sensitivitas kaki pada kelompok intervensi dan kelompok kontrol.

\section{PEMBAHASAN}

\section{Karakteristik Responden Berdasarkan Usia}

Usia responden pada kelompok intervensi setengahnya $50 \%$ adalah rentang usia lansia akhir yaitu (56-65 tahun) dan kategori usia responden pada kelompok kontrol sebagian besar yaitu 44,4 \% pada rentang usia lansia awal (46-55 tahun) yang mengalami neuropati periferal dengan nilai sensitivitas kaki yang berkurang.

Komplikasi DM dengan neuropati dapat menyerang para diabetisi dari berbagai usia. Semakin lama seseorang mengalami DM, maka risiko mengalami komplikasi juga meningkat. Hal ini dapat disebabkan karena faktor degeneratif, yaitu semakin menurunnya fungsi tubuh, khususnya kemampuan dari sel $\beta$ pankreas dalam memproduksi insulin (Betteng, Pangemanan, \& Mayulu, 2014).

Semakin bertambah usia pada penderita DM tipe 2 maka semakin menurun juga fungsi tubuhnya salah satunya adalah penurunan alirah darah ke daerah perifer sehingga menurunkan asupan nutrisi sampai kedaerah tersebut terutama pada daerah ektrimitas bawah, sehingga hal tersebut yang 
dapat menyebabkan peningkatan resiko terjadinya neuropati lebih buruk.

\section{Karakteristik Responden Berdasarkan Jenis Kelamin}

Responden berjenis kelamin perempuan lebih banyak mengalami neuropati periferal yaitu $61,1 \%$ pada kelompok intervensi dan $61,1 \%$ pada kelompok kontrol dibandingkan dengan jenis kelamin laki-laki yaitu 38,9\% pada kelompok intervensi dan 38,9 \% pada kelompok kontrol, hal ini dipengaruhi populasi perempuan yang menderita DM tipe 2 lebih banyak jumlahnya dibandingkan populasi laki-laki.

Perempuan memiliki risiko lebih besar untuk mengalami komplikasi neuropati. Hal ini berhubungan dengan paritas dan kehamilan, di mana keduanya adalah faktor risiko untuk terjadinya penyakit DM. Hasil penelitian dari Al-Rubeaan et al (2015) menyebutkan bahwa komplikasi neuropati pada pasien DM lebih banyak pada perempuan $(63 \%)$ dibandingkan dengan lakilaki (37\%) hal ini juga di dukung oleh penelitian Penelitian ini sejalan dengan penelitianya yang dilakukan oleh Purwanti \& Maghfirah, 2016 yang menyatakan bahwa sebagian besar penyandang diabetes melitus yang berjenis kelamin perempuan ${ }^{15}$.

Dengan demikian perempuan lebih rentan terkena neuropati dibandingkan dengan laki-laki karena faktor resiko DM pada perempuan lebih besar dari laki, terutama dipengaruhi oleh hormon estrogen yang merupakan faktor protektif terhadap penyakit athesklerosis, hal tersebut yang dapat menyebabkan jumlah neuropati periferal pada perempuan lebih tinggi

\section{Karakteristik Responden Berdasarkan lama menderita DM}

Responden dalam penelitian ini mengalami DM lebih dari 5 tahun yaitu 55,6 $\%$ pada kelompok intervensi dan $61,1 \%$ pada kelompok kontrol . Semakin lama seseorang menderita DM, risiko untuk mengalami komplikasi juga akan meningkat. Sebanyak $35-40 \%$ diabetisi, ditemukan adanya neuropati dengan durasi DM lebih dari 3 tahun dan $70 \%$ pada diabetisi dengan durasi DM lebih dari 5 tahun ${ }^{15}$.

Hal ini dikarenakan, pada diabetisi terjadi kelainan sel saraf yang terdapat pada sel-sel schwan, selaput myelin, dan akson. Gambaran kerusakan tersebut berupa demyelinisasi segmental, kerusakan akson, dan penebalan membran basal yang mengelilingi permukaan sel schwan. Semakin lama, akson sel saraf akan hilang sama sekali. Selain kelainan morfologi, pada diabetisi juga akan ditemukan adanya kelainan fungsional berupa gangguan kemampuan penghantaran implus, baik motorik maupun sensorik. Secara biokimiawi, akan ditemukan adanya kelainan dalam jumlah dan bentuk-bentuk protein sel saraf yang terkena ${ }^{16}$.

Semakin lama seseorang menderita DM tipe 2 maka kerusakan syaraf semakin besar terutama pada pada daerah perifer hal ini dipengaruhi oleh penurunan aliran darah sehingga mengurangi nutrisi syaraf untuk sampai kedaerah perifer

\section{Karakteristik Responden Berdasarkan Riwayat Merokok}

Hasil penelitian dengan masing-masing sebagian besar responden laki-laki memiliki riwayat merokok, sebanyak 85,71\% laki-laki memiliki riwayat merokok pada kelompok intervensi dan begitu juga pada kelompok kontrol 85,71\% memiliki riwayat merokok . Dan didapatkan hasil bahwa ada hubungan riwayat merokok dengan neuropati periferal.

Menurut penelitian Clair, C., Cohen, M.J., Eichler, F., Selby, K.J., Rigotti, N. A., 2015 dari 28 studi pustaka dengan total 27.594 menunjukan ada hubungan antar merokok dengan neuropati periferal. Kandungan nikotin yang terkandung dalam rokok akan menyebabkan kerusakan endotel 
kemudian terjadi penempelan dan agregasi trombosit yang selanjutnya akan terjadi kebocoran sehingga lipoprotein lipase akan memperlambat clearance lemak darah dan mempermudah timbulnya aterosklerosis. Adanya aterosklerosis ini akan memicu terjadi stres oksidatif ${ }^{16}$.

Dengan demikian orang yang merokok akan beresiko lebih besar terkena neuropati dibandingkan dengan orang yang tidak merokok, semakin lama seseorang mengkonsomsi rokok semakin besar terjadinya aterosklerosis yang dapat menyebabkan terjadinya neuropati.

\section{Karakteristik Responden Berdasarkan Hasil Cek GDS}

Setelah intervensi senam ergonomik Hasil Cek GDS sebelum intervensi $100 \%$ responden pada kelompok kontrol dan intervensi memiliki gula darah lebih dari 200 $\mathrm{mg} / \mathrm{dl}$ hal ini menunjukan semua responden mengalami kadar glukosa yang tinggi yang dikategorikan dalam tipe 2. Kadar gula darah yang tinggi dapat membuat aliran darah mengecil sehingga dapat merusak saraf di kaki dan telapak kaki, serta menurunkan kemampuan merasakan sensitifitas di kaki. Glikolisasi kolagen sebagai akibat dari penyakit DM yang lama dapat menyebabkan kaku struktur kapsuler dan ligament ${ }^{17}$.

Berdasarkan penelitian yang dilakukan Rosyida dan Safitri, 2016, pada pemeriksaan GDS (gula darah sewaktu), lebih banyak responden yang mengalami neuropati sedang dan berat dengan kadar GDS $\geq 200 \mathrm{mg} / \mathrm{dl}$ sedangkan responden yang mengalami neuropati ringan memiliki GDS 90-199 $\mathrm{mg} / \mathrm{dl}$.

Dengan demikian semakin tinggi GDS seseorang yang terkena DM tipe 2 semakin beresiko menyebabkan komplikasi neuropati periferal lebih berat hal ini karena gula darah yang tinggi dapat menyebabkan aliran darah menjadi menurun terutama pada daerah perifer sehingga akan menyebabkan asupan nutrisi berkurang

Identifikasi hasil Uji Sensitivitas Kaki Neuropati Periferal Diabetes Melitus tipe 2 sebelum dilakukan perawatan kaki

Sebelum dilakukan perawatan kaki terlebih dahulu dilakukan pengukuran sensitivitas kaki pasien DM tipe 2, didapatkan hasil bahwa dari pemeriksaan 18 kelompok intervensi mengunakan uji monofilamen, terdapat 14 yaitu $77,78 \%$ yang mengalami penurunan sensasi proteksi dan 18 kelompok kontrol menggunakan uji monofilamen, terdapat 13 responden yaitu $72,22 \%$ yang mengalami penurunan sensasi proteksi. sedangkan dari pemeriksaan 18 kelompok intervensi menggunakan uji garputala, terdapat 11 responden yaitu 61,11 $\%$ yang mengalami penurunan sensasi getaran dan 18 kelompok kontrol menggunakan uji garputala, terdapat 9 responden yaitu $50 \%$ mengalami penurunan sensasi getaran.

Hasil penelitian menunjukan bahwa sebagian besar responden memiliki gejala neuropati periferal yang diketahui melalui uji sensitivitas kaki menggunakan monofilamen dan garputala. Gejala yang dirasakan oleh responden berupa kaki yang sering kesemutan, rasa terbakar, dan tidak bisa merasakan benda benda yang diinjak oleh kaki. Hal ini sesuai dengan Said, (2015) Gejala Neuropati Periferal dapat dikeluhkan terjadi pada jari-jari kaki, kaki, tungkai kaki, tangan, telapak tangan, dan/atau jari-jari tangan dan meliputi penurunan sensasi terhadap perubahan suhu dan nyeri; kesemutan; perasaan geli, terbakar, atau nyeri; nyeri yang tajam; keram; alodinia; dan/atau kehilangan keseimbangan ${ }^{18}$.

Hal yang menyebabkan terjadinya penurunan sensitivitas kaki yaitu kadar glokosa darah yang tinggi sehingga menyebabkan aliran darah ke daerah perifer terganggu terutama pada bagian ekstimitas 
bawah hal ini sesuai dengan pendapat yang dikemukakan oleh Bates-Jensen, (2007) melalui Teori vaskular yaitu pada pasien Diabetic Neuropathy (DN) terjadi penurunan aliran darah ke endoneurium yang disebabkan oleh adanya resistensi pembuluh darah akibat hiperglikemia.

Kadar gula darah yang tinggi dapat membuat aliran darah mengecil sehingga dapat merusak saraf di kaki dan telapak kaki, serta menurunkan kemampuan merasakan sensitivitas di $\mathrm{kaki}^{17}$.

Gangguan dalam mengenali sensitivitas kaki diakibatkan oleh Kerusakan fungsi saraf sensorik yang terjadi karena mekanisme peningkatan stres oksidatif sehingga proses penghantaran implus terganggu ${ }^{19}$. Kerusakan saraf sensorik melibatkan serabut saraf kecil yang berfungsi untuk merasakan nyeri dan sensasi suhu, sedangkan serabut besar digunakan untuk persepsi vibrasi dan sensasi sentuhan $^{20}$. Gejala neuropati ini paling terasa pada tungkai bawah dan kaki sebelah kanan dan kiri ${ }^{21}$.

Penyebab utama neuropati periferal adalah diabetes melitus sehingga orang yang memiliki gula darah tinggi rentan untuk terkena neuropati periferal, neuropati periferal adalah komplikasi umum pada penderita DM tipe 2, hal ini disebabkan oleh gula darah yang tidak terkontrol dapat memperlambat aliran darah terutama pada daerah perifer sehingga menyebabkan asupan nutrisi berkurang dan syaraf pada daerah perifer kurang mendapatkan nutrisi yang cukup sehingga menyebabkan kerusakan pada syaraf.

Identifikasi Perubahan Uji Sensitivitas Kaki Neuropati Periferal Diabetes Melitus Tipe 2 Sesudah dilakukan Perawatan Kaki

Penelitian ini menggunakan perawatan kaki pada kelompok perlakuan dan pada kelompok kontrol hanya diberikan cara mengontrol gula darah. Sesudah dilakukan penelitian selama 3 bulan pada 18 kelompok intervensi dan 18 kelompok kontrol dilakukan pengukuran menggunakan monofilamen $10 \mathrm{~g}$ dan garputala $128 \mathrm{~Hz}$ didapatkan hasil bahwa terdapat perubahan pada sensitivitas kaki yaitu menjadi lebih baik, pada pemeriksaan monofilamen $10 \mathrm{~g}$ pada kelompok intervensi didapatkan 94,44 $\%$ yaitu sebanyak 17 responden sensitivitas kakinya menjadi normal, dan pada kelompok kontrol didapatkan 72,22\% yaitu sebanyak 13 responden sensitivitas kakinya menjadi normal, sedangkan pada pemeriksaan garputala $128 \mathrm{~Hz}$ pada kelompok intervensi didapatkan 88,89\% yaitu sebanyak 16 responden sensitivitas kakinya menjadi normal dan pada kelompok kontrol didapatkan $77,78 \%$ yaitu senyak 14 responden sensitivitas kakinya menjadi normal. terdapat peningkatan sensitivitas kaki pada kelompok intervensi dan kontrol, tetapi pada kelompok kontrol tidak sesignifikan pada kelompok intervensi.

Perawatan kaki yang baik dapat mencegah terjadinya komplikasi kaki diabetes secara dini. Pencegahan komplikasi diabetes melitus dapat membantu meningkatkan angka harapan hidup bagi penderita diabetes. Kebiasaan perawatan kaki yang baik pada responden sudah menunjukkan prosentase yang cukup besar. Menurut Kerri Wright (2010) perawatan kaki yaitu memeriksa kaki setiap hari, apakah ada perubahan warna, terjadi pembengkakan, nyeri atau mati rasa, memeriksa alas kaki seperti sepatu atau kaus kaki yang digunakan untuk memastikan bahwa alas kaki sesuai dan tidak menyebabkan lecet pada kaki, mencuci kaki setiap hari menggunakan sabun dan air hangat serta melembabkannya, mengeringkan kaki dengan hati-hati, khususnya diantara sela-sela jari kaki, serta menggunting kuku

Perendaman air hangat dapat digunakan secara luas. Rendam air hangat merupakan kondisi kaki yang oleh kontak dari kaki ke air hangat. Rendam kaki air hangat dilakukan 
pada suhu $38-39^{\circ} \mathrm{C}$. Rendam air hangat yang diberikan pada pasien DM dapat memperlancar aliran darah pada vena sehingga terjadi reaksi vasodilatasi pada pembuluh darah. Suhu ditentukan maka efek pada sirkulasi arah pasien DM lebih baik ${ }^{22}$.

Manfaat air panas dapat dipergunakan secara luas dalam pengobatan karena memiliki efek dan manfaat yang benar. Pada jaringan akan terjadi metabolisme seiring dengan peningkatan pertukaran antara zat kimia tubuh dengan cairan tubuh, lalu efek biologis yaitu panas dapat menyebabkan dilatasi pembuluh darah yang dapat mengakibatkan peningkatan sirkulasi darah $^{22}$.

Dengan melakukan perawatan kaki yaitu mencuci dan merendam kaki dengan air hangat dapat memperlancar sirkulasi darah di kaki sehingga asupan nutrisi sampai ke kaki dan membuat syaraf syaraf pada kaki akan lebih sensitif, gejala gejala pada kaki yang dirasakan penderita neuropati akan berkurang, dan akan mencegah komplikasi lebih lanjut seperti ulkus diabetikum. Efek dari perawatan kaki ini akan dirasakan pada pasien yang melakukannya secara rutin dan berkesinambungan.

\section{Analisis Perubahan Uji Sensitivitas Kaki Neuropati Periferal pada Diabetes Melitus Tipe 2 Sebelum dan Sesudah dilakukan Perawatan Kaki}

Setelah dilakukan uji statistik didapatkan $P$ value $=0,000$ pada kelompok intervensi dan $P$ value $=0,000$ pada keompok kontrol hal ini membuktikan bahwa terdapat pengaruh yang signifikan perawatan kaki terhadap perubahan uji sensitivitas kaki neuropati periferal pada pasien DM tipe 2 .

Penelitian yang dilakukan oleh Embuai, s., Lestari, P., Ulfina, e., (2017) bahwa setelah dilakukan intervensi perawatan kaki selama 3 bulan didapatkan bahwa semua responden yang mengalami neuropati periferal sebanyak 41 responden mengalami perbaikan kearah positif dan 6 responden masih mengalami neuropati ${ }^{10}$, sedangkan Penelitian dan menurut penelitian Ngadiluwih, (2018). Hasil analisa dan interprestasi data yang dilakukan pada 35 responden mengenai sensitivitas kaki setelah melakukan perawatan kaki, diperoleh hasil bahwa sebanyak 33 (94,3\%) responden yang masalah sensitivitas kaki mengalami perubahan nilai negatif menjadi positif sensitivitas kaki sebanyak 33 responden, 2 $(5,7 \%)$ responden tidak ada perubahan nilai sensitivitas $^{23}$.

Hasil penelitian ini senada dengan penelitian sebelumnya yaitu penelitian di Spanyol yang dilakukan oleh Calle dkk. Pada 318 diabetisi dengan neuropati dilakukan perawatan kaki yang dilakukan dengan menjaga sirkulasi darah kaki dihasilkan kelompok yang tidak melakukan perawatan kaki 13 kali berisiko terjadi ulkus diabetika dibandingkan kelompok yang melakukan perawatan kaki secara teratur $\left({ }^{24}\right.$.

Menurut Saskatchewan Ministry of health (Departemen Kesehatan Kanada, 2010) kaki diabetik jika sudah terjadi memerlukan waktu yang lama untuk penyembuhan, maka diperlukan pencegahan agar tidak terjadi. Tindakan pencegahan kaki diabetik terdiri dari mencari informasi tentang kaki diabetik, identifikasi faktor resiko, manajemen diabetes melitus, perawatan kaki, edukasi, Menurut The Centers for Disease Control and Prevention (2009) bahwa perawatan kaki secara teratur dapat mengurangi penyakit kaki diabetik sebesar $50-60 \%$ yang mempengaruhi kualitas hidup.

Perawatan kaki harus dilakukan secara rutin dan teratur supaya sensitivitas kaki menjadi normal dan dapat meningkatkan kualitas hidup pasien DM tipe 2. Perawatan kaki yang baik merupakan upaya preventif untuk mencegah komplikasi lebih lanjut terutama ulkus diabetikum sehingga akan meningkatkan kualitas hidup penderita DM 
tipe 2, upaya ini harus didukung oleh tenaga kesahatan, keluarga, dan pribadi dalam melakukan perawatan kaki, perawat memberikan peran penting dalam melakukan pendidikan kesehatan untuk menjaga pola makan dan nutrisi serta melakukan aktivititas seperti latihan kaki untuk mendukung keberhasilan perawatan kaki pada pasien DM tipe 2. Oleh sebab itu perawatan kaki harus menjadi intervensi mandiri yang harus dilakukan pasien DM tipe 2 untuk mencegah terhjadinya perlukaan pada kaki.

\section{SIMPULAN SARAN}

Usia 46-65 tahun, jenis kelamin perempuan, lama menderita DM lebih dari 5 tahun, hasil cek GDS lebih dari $200 \mathrm{mmHg}$, dan responden dengan riwayat merokok memiliki prevalensi neuropati perifer yang lebih tinggi.

Uji sensitivitas kaki sebelum intervensi hampir seluruhnya mengalami penurunan sensitivitas yaitu dengan nilai 1-7 pada kelompok intervensi dan kelompok kontrol untuk uji monofilamen $10 \mathrm{~g}$ sedangkan untuk uji garputala $128 \mathrm{~Hz}$ dengan nilai 3-17 pada kelompok intervensi dan 2-18 pada kelompok kontrol.

Uji sensitivitas kaki sesudah dilakukan intervensi hampir seluruhnya mengalami perubahan sensitivitas kearah yang lebih baik yaitu dengan nilai 5-10 untuk intervensi dan 3-8 pada kelompok kontrol untuk uji monofilamen $10 \mathrm{~g}$ sedangkan untuk uji garputala $128 \mathrm{~Hz}$ dengan nilai 1-15 pada kelompok intervensi dan 2-15 pada kelompok kontrol.

Berdasarkan hasil penelitian dapat disimpulkan bahwa terdapat pengaruh perawatan kaki terhadap perubahan uji sensitivitas kaki neuropati periferal pada pasien DM tipe 2 di wilayah UPTD Puskesmas Pontianak Selatan. Penelitian ini membutuhkan waktu 3 bulan sehingga diperlukan pengontrolan terhadap aktivitas perawatan kaki pasien DM tipe 2.

\section{REKOMENDASI}

Hasil penelitian perawatan kaki ini dapat dijadikan sebagai salah satu intervensi nonfarmakologi untuk penderita DM tipe 2 yang mengalami neuropati periferal. Perawatan kaki ini juga dapat dijadikan sebagai salah satu aktifitas rutin untuk untuk mengatasi sensitivitas kaki.

\section{DAFTAR PUSTAKA}

1. Taylor, E. S. 2012. Chapter 7. Health Psychology. New York: PT. McGraw Hill.

2. Soegando. 2015. Penatalaksanaan Diabetes Melitus Terpadu. Jakarta: FKUI

3. Puji. I., Supriyatno. H., Santoso. A., 2015. Pengaruh Latihan Fisik; Senam Aerobik Terhadap Penurunan Kadar Gula Darah Pada Penderita DM Tipe 2 di Wilayah Puskesmas Bukateja Purbalingga. Media Ners.1:89-99

4. International Diabetes Federation. 2017, IDF Western Pasific Member,http://www.idf.org/ournetwork/ regionsmembers/westernpasific/member 1104-Indonesia.html

5. RISKESDAS. 2018. Riset Kesehatan Dasar tentang Penyakit Diabetes. Diakses pada tanggal 20 November 2018. www.litbang.depkes.go.id

6. Witasari. 2009. Hubungan tingkat pengetahuan, asupan karbohidrat dan serat dengan pengendalian kadar glukosa darah. penelitian sains \& teknologi, 10 (2).

7. Suyanto. 2017. Gambaran Karakteristik Penderita Neuropati Perifer Diabetik. Jurnal Keperawatan dan Pemikiran Ilmiah. 3(1). 1-6

8. Smeltzer, S. C \& Bare, B. G. 2002. Buku Ajar Keperawatan Medikal Bedah Brunner dan Suddarth (Ed.8, Vol. 1,2). Jakarta: EGC 
9. Hidayat, A \& Uliyah, M. 2014. Pengantar kebutuhan dasar manusia. Jakarta: Salemba medika.

10. Embuai, s., Lestari, P., Ulfina, e. 2017. Pengaruh Edukasi Perawatan Kaki dan Senam Kaki Terhadap Upaya Pencegahan Risiko Foot Ulcer pada Klien Diabetes Melitus. Jurnal Penelitian Kesehatan Suara Forikes. 8 (4). 180-190

11. Wang, F., et al. 2017. Diagnostic Accuracy of Monofilamen Tests for Detecting Diabetic Periferal Neuropathy: A Systematic Review and Meta-Analysis. Journal of Diabetes Research, 1-12.

12. Rosyida, K. 2016. Gambaran Neuropati Perifer pada Diabetesi di Wilayah Kerja Puskesmas Kedungmungu Semarang. Skripsi. Universitas Diponegoro

13. Yusriani, Alwi, M.K. 2018. Buku Ajar Promosi Kesehatan dan Pemberdayaan Masyarakat. Yogyakarta: Medical Book.

14. Alligood, M. R. 2014. Nursing theory \& their work (8th ed). The CV Mosby Company St. Louis. Toronto. Missouri: Mosby Elsevier. Inc

15. Al-rubeaan, K., Derwish, M.A., Ouizi, S., \& Youssef, A.M. 2015. Diabetic Foot Complications and Their Risk Factors From A Large Retrospective Cohort Study. NCBI, 53, 1-17

16. Hastuti, R. 2008. Faktor-Faktor Risiko Ulkus Diabetika pada Penderita Diabetes Melitus Studi Kasus di RSUD Dr. Moewardi Surakarta. Skripsi: Universitas Diponegoro.

17. Parisi, M. C. R., Neto, A. M., Menezes, F. H., Gomes, M. B., Teixeira, R. M., \& Egídio, J. 2016. Baseline Characteristics and Risk Factors for Periferal Neuropathy, Amputation and Severe Neuropathy in Diabetic Foot at Risk: The BRAZUPA Study. BioMed Central, 1-8.

18. Said, G. 2015. Diabetic neuropathy. Advanced studies in medicine. 11:457459
19. Deli, G., Bosnyak, E., Pusch, G., Komoly, S., \& Feher, G. 2014. Diabetic Neuropathies: Diagnosis and Management. Neuroendoocrinology. 98(4), 267-280

20. Meiti, F. 2012. Clinical Approach and Electrodiagnostic Studies. Skripsi: Universitas Andalas.

21. Hidayat, A \& Uliyah, M. 2014. Pengantar kebutuhan dasar manusia. Jakarta: Salemba medika

22. Eversden, R. 2008. Patient With Rheumatoid Arthritis Fell Better After Excercuse in Warm Water than After Similar Exercise on land. Autralian and New zeland : Allied Health

23. Ngadiluwih, M. S. 2018. Pengaruh Perawatan Kaki Terhadap Sensitivitas Kaki pada Penderita Diabetes Melitus Tipe 2. Skripsi: Sekolah Tinggi Ilmu Kesehatan Insan Cendikia Medika.

24. Calle, $\quad$ Pascual,Duran,A.,. 2010. Reduction in Foot Ulcer Incidence, Diabetes Care, Spain. 